\title{
Foreword
}

\section{From the President's Desk}

\author{
Ramesh Mehta MD FRCP OBE \\ President, British Association of Physicians of Indian Origin \\ Ramesh.mehta@bapio.co.uk
}

Cite as: Mehta, R. (2019) Foreword from the President's desk. Sushruta Nov 12(1):7 DOI: $\underline{10.38192 / 12.1 .2}$

To mark the 150th Birth Anniversary of Mahatma Gandhi, while we have Gandhi on our cover page; I recollect one of his core messages: "Those who behave like worms should not blame others for trampling upon them". As an organisation, we have tried to follow his advice and have always stood up for fairness and justice. By dedicating this issue of Sushruta to Gandhi, we pay tribute to a great soul, who not only guided the struggle for independence of India but dedicated his life to promoting 'Truth \& non-violence." A unique and unparalleled human that many generations would note as 'Timeless Mahatma'.

BAPIO continues to raise issues and challenges the establishment while at the same time collaborating with it to find solutions. Our major concerns continues to be differential attainment of BAME doctors and unfair complaint processes against them. Hindrance in the career progression of BAME staff, stops them from achieving their potential. Unhappy and demoralised staff is bad news for patient care and as a huge loss of talent to the nation. Fortunately, thanks to the NHS Long Term Plan, there is consideration for supporting and looking after the happiness of staff. We will be closely watching their work.

Unfair and unjust complaints is a major problem in all the trusts. The annual survey of Workforce Race Equality Standard (WRES) continues to reveal bullying, harassment and low morale of BAME staff. As a solution BAPIO is developing partnership with hospital trusts to provide early conflict resolution training and cultural training to staff to promote equality and inclusion.

I am pleased to commend this special edition of Sushruta that has number of interesting content and hope that readers will find it informative. Finally, I would like to thank the Dr Indranil Chakravorty, Convener and Dr Satheesh Mathew, Chair of the Organising committee of the conference for their contribution. Thanks also to the Managing Editor, Buddhdev Pandya MBE for his work in curating and designing this edition of Sushruta. 